Article

\title{
Green Synthesis and Characterization of Pullulan Mediated Silver Nanoparticles through Ultraviolet Irradiation
}

\author{
Muhammad Jamshed Khan ${ }^{1,2} \mathbb{D}$, Suriya Kumari ${ }^{1, *}$, Kamyar Shameli ${ }^{3}$, Jinap Selamat ${ }^{1}$ and \\ Awis Qurni Sazili ${ }^{1}$ \\ 1 Institute of Tropical Agriculture and Food Security, Universiti Putra Malaysia (UPM), \\ Serdang 43400, Malaysia \\ 2 Faculty of Veterinary Sciences, Bahauddin Zakariya University, Multan 60800, Pakistan \\ 3 Malaysia-Japan International Institute of Technology, Universiti Teknologi Malaysia, \\ Jalan Sultan Yahya Petra, Kuala Lumpur 54100, Malaysia \\ * Correspondence: s_kumari@upm.edu.my; Tel.: +60-89471172
}

Received: 12 June 2019; Accepted: 2 July 2019; Published: 26 July 2019

check for updates

\begin{abstract}
Nanoparticles (NPs) are, frequently, being utilized in multi-dimensional enterprises. Silver nanoparticles (AgNPs) have attracted researchers in the last decade due to their exceptional efficacy at very low volume and stability at higher temperatures. Due to certain limitations of the chemical method of synthesis, AgNPs can be obtained by physical methods including sun rays, microwaves and ultraviolet (UV) radiation. In the current study, the synthesis of pullulan mediated silver nanoparticles (P-AgNPs) was achieved through ultraviolet (UV) irradiation, with a wavelength of $365 \mathrm{~nm}$, for $96 \mathrm{~h}$. P-AgNPs were formed after $24 \mathrm{~h}$ of UV-irradiation time and expressed spectra maxima as $415 \mathrm{~nm}$, after 96 h, in UV-vis spectroscopy. The crystallographic structure was "face centered cubic (fcc)" as confirmed by powder X-ray diffraction (PXRD). Furthermore, high resolution transmission electron microscopy (HRTEM) proved that P-AgNPs were covered with a thin layer of pullulan, with a mean crystalline size of $6.02 \pm 2.37$. The average lattice fringe spacing of nanoparticles was confirmed as $0.235 \mathrm{~nm}$ with quasi-spherical characteristics, by selected area electron diffraction (SAED) analysis. These green synthesized P-AgNPs can be utilized efficiently, as an active food and meat preservative, when incorporated into the edible films.
\end{abstract}

Keywords: pullulan; silver nanoparticles; UV irradiation; green synthesis

\section{Introduction}

Metal nanoparticles (NPs) have been frequently investigated by the researchers for their multi-dimensional applications after their synthesis in 1959 by Richard Feynman, with a size ranging from $1 \mathrm{~nm}$ to $100 \mathrm{~nm},[1-3]$. NPs exhibited a new behavior of efficiency at even very low concentration [4]. The recent trend of nanotechnology research has been diverted to antimicrobial food packaging, delivery of nano-medicines/drugs, gene delivery vectors, nano-imaging and Biosensors for cancer diagnosis, and polymeric nano-composite wound dressing [3,4].

Among metal NPs, the utilization of silver nanoparticles (AgNPs) in the biomedical sector, animal and human nutrition, electronic industry and food preservation is remarkable [5]. AgNPs, as compared to other metal NPs, exhibit very low volatility, with tolerance against high temperatures as compared to other nanoparticles [6]. Moreover, AgNPs can restrain the growth of the microorganisms (including Gram positive and Gram negative bacterial strains; fungi) from the initial contact and further penetration into the cellular membrane of the microbes $[7,8]$. 
Various chemical and physical techniques have been reported for the synthesis of AgNPs. The chemical techniques have certain limitations including strict reaction protocols, toxic reagents, time consumption and unstable NPs [9]. A new and relatively safer concept has been presented by Raveendran et al. [10] as the "green synthesis" of AgNPs. The synthesis of AgNPs, with reduced size and better shape, through direct physical techniques, is another green and promising sector [11]. These physical techniques mainly include synthesis by sun rays, microwave radiation, gamma radiation or ultraviolet (UV) irradiations $[9,12,13]$. For the physical methods, the toxicity, economy and benign biological nature of the compounds should not be ignored [14-16]. The organic biopolymers are economical, environment friendly and exhibit no or very low toxic nature for the physical synthesis of AgNPs [12,13,17-21]. These organic biopolymers mainly include the exo-polysaccharides (EPS) obtained from bacteria, algae and fungi [10,22-24].

Pullulan is an extra cellular polysaccharide produced by a fungal species Aureobasidium pullulans [25]. For the synthesis of AgNPs, few studies have been reported to utilize pullulan as a green reducing, capping and stabilizing agent [26-29]. Pullulan mediated silver nanoparticles (P-AgNPs) can be applicable in food and meat preservation, drug carrying and therapeutic studies [30]. Ganduri et al. [31] reported that AgNPs synthesized from the increasing concentrations of pullulan, improved the formation of AgNPs with better quality and quantity [11,31].

The direct and green synthesis of AgNPs mediated by pullulan (reducing and capping agent), through UV irradiation, has not been reported yet. Thus, the present study was planned to use UV irradiations, as a physical green technique, for the green synthesis of P-AgNPs. The impact of increasing time of UV irradiation (from $0 \mathrm{~h}$ to $96 \mathrm{~h}$ ) on the synthesis, size and distribution of AgNPs was also studied.

\section{Materials and Methods}

\subsection{Materials}

The materials for the synthesis of P-AgNPs were pullulan (97.0\% pure, food grade, obtained from Aureobasidium pullulans; Sigma-Aldrich, St. Louis, $\mathrm{MO}$, USA), Silver nitrate $\left(\mathrm{AgNO}_{3}\right)(\mathrm{R} \& \mathrm{M}$, London, UK) and deionized water (Sigma-Aldrich). All the reagents used in the study were of analytical grade and no purification was conducted before their use. Pullulan was dried at $100{ }^{\circ} \mathrm{C}$ for $24 \mathrm{~h}$ before use.

\subsection{Green Synthesis of Pullulan Mediated Silver Nanoparticles}

Three concentrations of pullulan were prepared as per the procedure reported by Shameli et al. [13] with modifications. The 1.0, 2.0 and $4.0 \mathrm{~g}$ of pullulan powder, equal to 5,10 and $20 \%(\mathrm{w} / \mathrm{v})$,were stirred with $200 \mathrm{~mL}$ of deionized water for $1.0 \mathrm{~h}$ at $500 \mathrm{rpm}$ at $24-25^{\circ} \mathrm{C}$.

A clear solution was obtained after $60 \mathrm{~min}$ of stirring. Three concentrations of $\mathrm{AgNO}_{3}$ aqueous solution $(0.02,0.50$, and $1.0 \mathrm{M})$ were produced by dissolving the calculated masses of $\mathrm{AgNO}_{3}$ in deionized water. To synthesize P-AgNPs, $250 \mathrm{~mL}$ of each pullulan solution (5, 10, and $20 \mathrm{wt} . \%)$ was mixed with an equal volume of the aqueous solutions of $\mathrm{AgNO}_{3}$. The assorted solutions were stirred thoroughly for $1.0 \mathrm{~h}$ at $65^{\circ} \mathrm{C}$ for $500 \mathrm{rpm}$ to complete the chemical reaction.

After stirring, the obtained suspensions were clear but viscous. These suspensions were put under ultraviolet radiation with a wavelength of $365 \mathrm{~nm}$ and the magnetic stirring speed of $195 \mathrm{rpm}$. UV irradiation was done by an ultraviolet reactor (ChECA, UTM, Kuala Lumpure, Malaysia) with a power of $450 \mathrm{~W}$. The feature of the UV-reactor bulb was UV-C Radiation ( 200 to $280 \mathrm{~nm}$ ) (Philips, TUV 8W, G8 T5, Kuala Lumpure, Malaysia). The irradiation process was done for 1, 3, 6, 8, 12, 24, 48, 64, and $96 \mathrm{~h}$ (A1-A9). After UV irradiation, the suspensions were centrifuged $25^{\circ} \mathrm{C}$ for $30 \mathrm{~min}$ to obtain the pellets of P-AgNPs. 


\subsection{Characterization of Pullulan Mediated Silver Nanoparticles}

Pullulan mediated silver nanoparticles (P-AgNPs) were characterized [9,12,13] through ultraviolet-visible spectroscopy (UV-vis) by a U-5100, UV-vis spectrophotometer (Hitachi, High Technologies Co., Tokyo, Japan) with a wavelength range of $220 \mathrm{~nm}$ to $800 \mathrm{~nm}$. The analysis of the structure was conducted through powder X-ray diffraction (PXRD) (PANanalytical EMPYREAN, Eindhoven, The Netherlands), Xpert High score Plus (V.14.0; PANanalytical EMPYREAN) at a lower angle of $30^{\circ}-80^{\circ}$ and scan with a speed of $2^{\circ} / \mathrm{min}$. The topographic analysis was performed by field emission scanning electron microscopy (FESEM) using a JSM 7600 F FESEM (JEOL Ltd., Tokyo, Japan). High-resolution transmission electron microscopy (HRTEM) was conducted through a JEM 2100F filed emission electron microscope (JEOL Ltd.) with a high resolution of $200 \mathrm{kV}$ using a $\mathrm{LaB}_{6}$ electron gun. Zeta potential of P-AgNPs was confirmed by a Litesizer 500, particle analyzer (Anton paar USA Inc., Ashland, VA, USA) while Fourier transform infrared spectroscopy (FT-IR) was conducted, with the spectral range of $500 \mathrm{~cm}^{-1}$ to $4000 \mathrm{~cm}^{-1}$, by using an IRTracer 100 Fourier transform infrared spectrophotometer (SHIMADZU Corp., Kyoto, Japan). The colloidal solution was centrifuged through a refrigerated micro-centrifuge $5810 \mathrm{R}$ (Sigma-Aldrich) to obtained P-AgNPs pellets.

Most of the characterization was performed with the colloidal solution dissolved in distilled water, while P-AgNPs powder was used for PXRD and FESEM analyses. Statistical analysis of the data was done by using SPSS software to measure the mean crystalline size (V.20.0, IBM Corp., Armonk, NY, USA).

\section{Results and Discussion}

In the present study, AgNPs were synthesized by UV irradiation successfully and pullulan was used as "stabilizer". Further, the impact of irradiation time on the formation of NPs along with the size of NPs was also considered. Pullulan $10 \%(\mathrm{w} / \mathrm{v})$ solution along with $0.50 \mathrm{M} \mathrm{AgNO}_{3}$ aqueous solution showed the formation of P-AgNPs. The formation of P-AgNPs was confirmed by the dark color of the colloidal suspension, after $96 \mathrm{~h}$ of UV irradiation [13] (Figure 1).

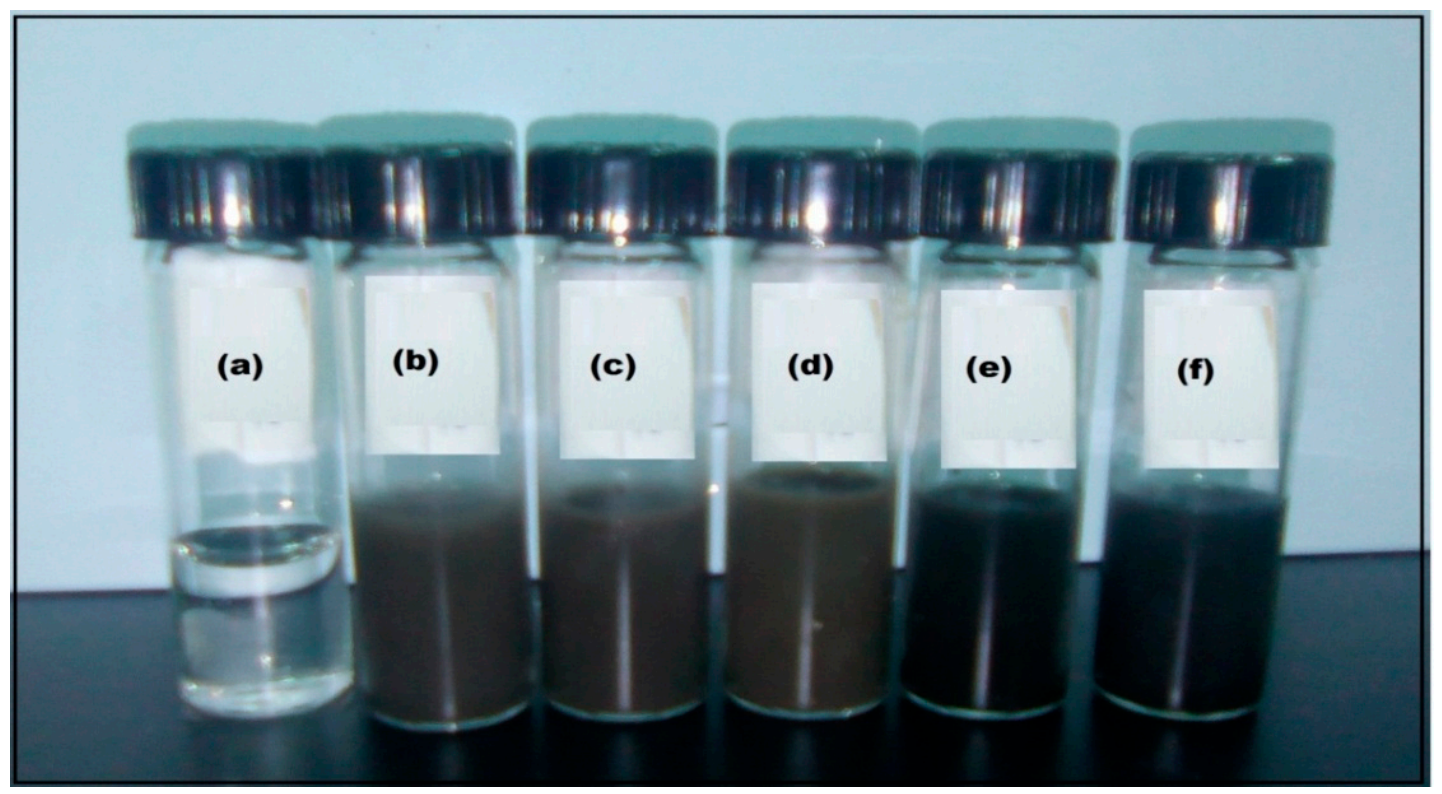

Figure 1. Characteristic changes in the color of pullulan solutions before and after irradiation: Pullulan/Ag ion, after 0, 12, 24, 48, 64, $96 \mathrm{~h}$ (a-f, respectively).

The formation of NPs was due to the reduction of $\mathrm{AgNO}_{3}$, changing the color of clear colloidal solution into light gray, then gray, and finally darker gray [13,32]. Our results are in agreement with 
the results as reported by Kanmani and Lim [32], Shameli et al. [13], and Saravanan et al. [24] for the formation of AgNPs by the reduction of $\mathrm{AgNO}_{3}$. The chemical structure of pullulan consists of repeating units of malto-triose connected with $\alpha-(1-6)$ linkages, providing solubility and flexibility to pullulan [33]. During the reduction process, the produced AgNPs were attracted by the amino radicals $\left(\mathrm{NH}_{2}\right)$ and hydroxyl $(\mathrm{OH})$ ends of malto-triose units of pullulan [13]. As a result, pullulan acts as a strong protective layer and a highly functional coating for AgNPs, with better stability in the solution over the time [30].

The impact of pullulan, as reducing and capping agent, on the formation of P-AgNPs was proven by ultraviolet visible (UV-vis) spectroscopy after various irradiation times (Figure 2). The UV-vis spectroscopic peaks were recorded from wavelengths 300-800 nm, where NPs formed a broad surface plasma resonance ultraviolet absorption band in the wavelength range of 380-480 nm [24].

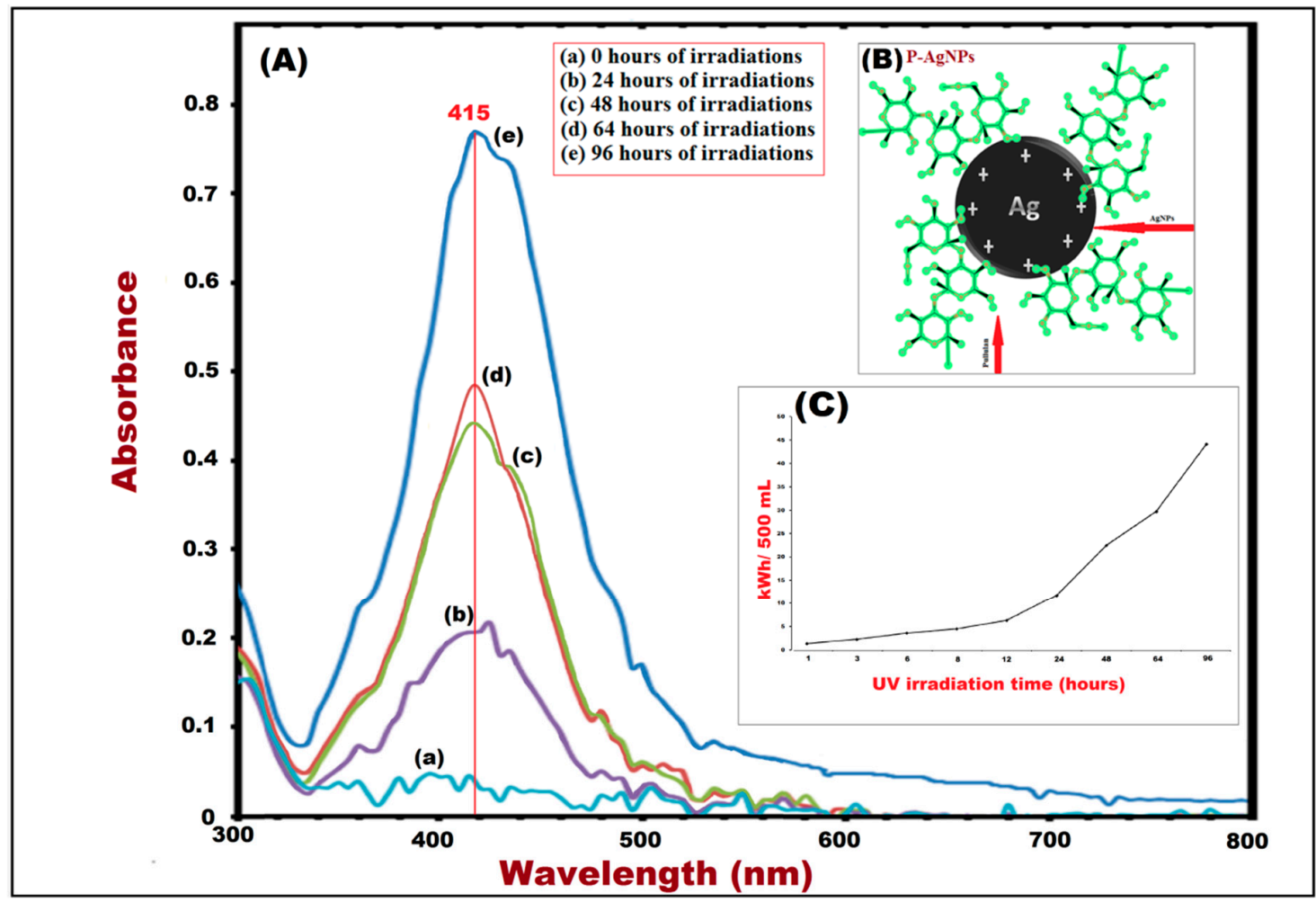

Figure 2. (A) UV-vis spectra maxima of P-AgNPs after $96 \mathrm{~h}$ of UV irradiation. (B) AgNPs surrounded by pullulan. (C) Power consumption curve for UV irradiation time.

It was also observed that P-AgNPs, formed in the colloidal solution after $96 \mathrm{~h}$ of irradiation, expressed a wavelength peak at $415 \mathrm{~nm}$. It was due to the fact that the AgNPs absorb UV radiation in the visible range of electromagnetic spectrum of $380 \mathrm{~nm}$ to $450 \mathrm{~nm}$, because of surface plasmon resonance (SPR) transition of AgNPs [17,34].

Therefore, based on the achieved results, pullulan with $10 \%$ concentration showed the formation of P-AgNPs, confirmed by the UV-vis spectra, indicating the impacts of pullulan concentrations, as well as UV irradiation time, on AgNPs formation (Figure 2). Pullulan mediated silver nanoparticles (P-AgNPs) formed after $24 \mathrm{~h}$ from UV-irradiation time, and the peak intensities were observed after 48, 64 and $96 \mathrm{~h}$ (Figure 2). This long-term study was related to evaluate the effect of radiation on the size and distribution of AgNPs. During that period we witnessed two phenomena at different times: contained aggregation at the beginning, and disaggregation at the end of radiation time. It was confirmed that the size of NPs was also reduced as the irradiation time increased from $0 \mathrm{~h}$ to $96 \mathrm{~h}$. The power consumption (power $\times$ time), during irradiation, was recorded as 10.80 (at $24 \mathrm{~h}$ ) to 43.20 (at $96 \mathrm{~h}$ ) kWh/500 mL of colloidal solution for P-AgNPs synthesis (Table 1, Figure 2C). 
Table 1. Power consumption data for UV irradiation during the synthesis of P-AgNPs.

\begin{tabular}{ccc}
\hline Samples & UV Irradiation Time (h) & Kilo Watt Hour (kWh)/500 $\mathbf{~ L L}$ \\
\hline A1 & 1 & 0.45 \\
A2 & 3 & 1.35 \\
A3 & 6 & 2.70 \\
A4 & 8 & 3.60 \\
A5 & 12 & 5.40 \\
A6 & 24 & 10.80 \\
A7 & 48 & 21.60 \\
A8 & 64 & 28.80 \\
A9 & 96 & 43.20 \\
\hline
\end{tabular}

The UV irradiation induced reduction process has been provided below:

$$
\begin{gathered}
\mathrm{AgNO}_{3} \stackrel{\text { UV-irradiation }}{\longrightarrow}\left(\mathrm{Ag}^{+}\right)+\mathrm{NO}_{3}^{-} \\
\left(\mathrm{Ag}^{+}\right)+\mathrm{e}^{-}(\mathrm{eq}) \stackrel{\text { reduction }}{\longrightarrow}(\mathrm{Ag})^{\circ} \\
(\mathrm{Ag})^{\circ}+\left(\mathrm{Ag}^{+}\right) \rightarrow\left(\mathrm{Ag}^{+}\right)^{2} \\
\mathrm{n}\left(\mathrm{Ag}^{+}\right)+\left(\mathrm{Ag}^{+}\right)^{2} \rightarrow\left(\mathrm{Ag}^{+}\right)^{\mathrm{n}} \\
\left(\mathrm{Ag}^{+}\right)^{\mathrm{n}}+\mathrm{e}^{-}(\mathrm{eq})^{\mathrm{n}} \rightarrow(\mathrm{Ag})^{\mathrm{n}}
\end{gathered}
$$

$\left(\mathrm{Ag}^{+}\right)$is the nano-cluster of the silver obtained from silver precursor $\left(\mathrm{AgNO}_{3}\right)$ and $\mathrm{e}^{-}(\mathrm{eq})$ are the electrons in the aqueous solution. After UV irradiation of pullulan/ $\mathrm{AgNO}_{3}$ colloidal solution, $\mathrm{Ag}^{+}$was, first, reduced to $(\mathrm{Ag})^{\circ}$, then $\left(\mathrm{Ag}^{+}\right)^{\mathrm{n}}$, leading towards the formation of $(\mathrm{Ag})^{\mathrm{n}}$ by the large number of aqueous electrons produced during the process [13]. Ultraviolet light covers a wave length spectrum from 100 to $380 \mathrm{~nm}$ and is sub-divided into three regions by wavelength including UV-A (320-400 nm), UV-B (280-320 nm), and UV-C (200-280 nm). UV-C is considered as the most energetic ultraviolet radiation [11]. Therefore, in this study, UV-C was used for the reduction of $\mathrm{Ag}^{+}$to $(\mathrm{Ag})^{\mathrm{n}}$.

It was possible to control the synthesis, size, and the shape of AgNPs surrounded by pullulan, by irradiation time as expressed by UV-vis spectra [12]. UV irradiation induced the reduction of the AgNPs precursor in the presence of pullulan solution [12,13]. Photo-chemical induced reduction of $\mathrm{AgNO}_{3}$ into AgNPs, in the presence of a polysaccharide capping agent, can not only control the sizes of NPs, but also their shapes [35].The prolonged exposure of $\mathrm{AgNO}_{3}$ colloidal solution containing silver cation ions causes the heating of AgNPs, resulting in their breakdown into smaller sized NPs [35]. As the irradiation time increased, the size of the synthesized AgNPs was reduced. This can be considered as the irradiation time dependent factor to control the synthesis, size, and shape of nanoparticles [36,37].

Our results are in agreement with Pandey et al. [34], Esumi et al. [35], Kuthirummal et al. [36], and Huang et al. [37] with respect to irradiation time controlling the size and shape of NPs.

The crystalline nature along with the topography of P-AgNPs, synthesized after $96 \mathrm{~h}$ of irradiation, was further confirmed by powder X-ray diffraction (PXRD). It can be observed that the crystalline nature of P-AgNPs was confirmed as crystalline silver (Figure 3). The nanoparticles exhibited four silver peaks in PXRD analysis at 2 theta/degree, i.e., $111\left(38.17^{\circ}\right), 200\left(44.33^{\circ}\right), 220\left(64.49^{\circ}\right)$, and 311 $\left(77.44^{\circ}\right)$. These peaks are consistent with $\mathrm{Ag}^{\circ}$ Peak Ref. No. 00-004-0783 (99.9\% pure silver; fcc) confirming their topographic nature as "face centered cubic (fcc)" [30]. From PXRD results, it is possible to estimate the average crystalline size of P-AgNPs by using the Debye-Scherrer's equation which is given as shown below;

$$
\boldsymbol{n}=K \lambda / \beta \cos \theta
$$


where $\boldsymbol{n}$ is the mean crystalline size, $K$ is Sherrer's constant (shape factor) with value 0.94 for spherical crystallites with cubical symmetry, $\lambda$ is X-ray wavelength (1.54 $\AA$; for powder samples only), $\theta$ is the Bragg angle and $\beta$ is the line broadening at half of the XRD peak [38]. The confirmation of actual crystalline size was conducted by high resolution transmission electron microscopy (HRTEM). Nevertheless, PXRD patterns are the main characteristic of P-AgNPs, also in concordance with the findings of Coseri et al. [30]; Bankura et al. [17]; Kanmani and Lim, [32] and Roopan [20].

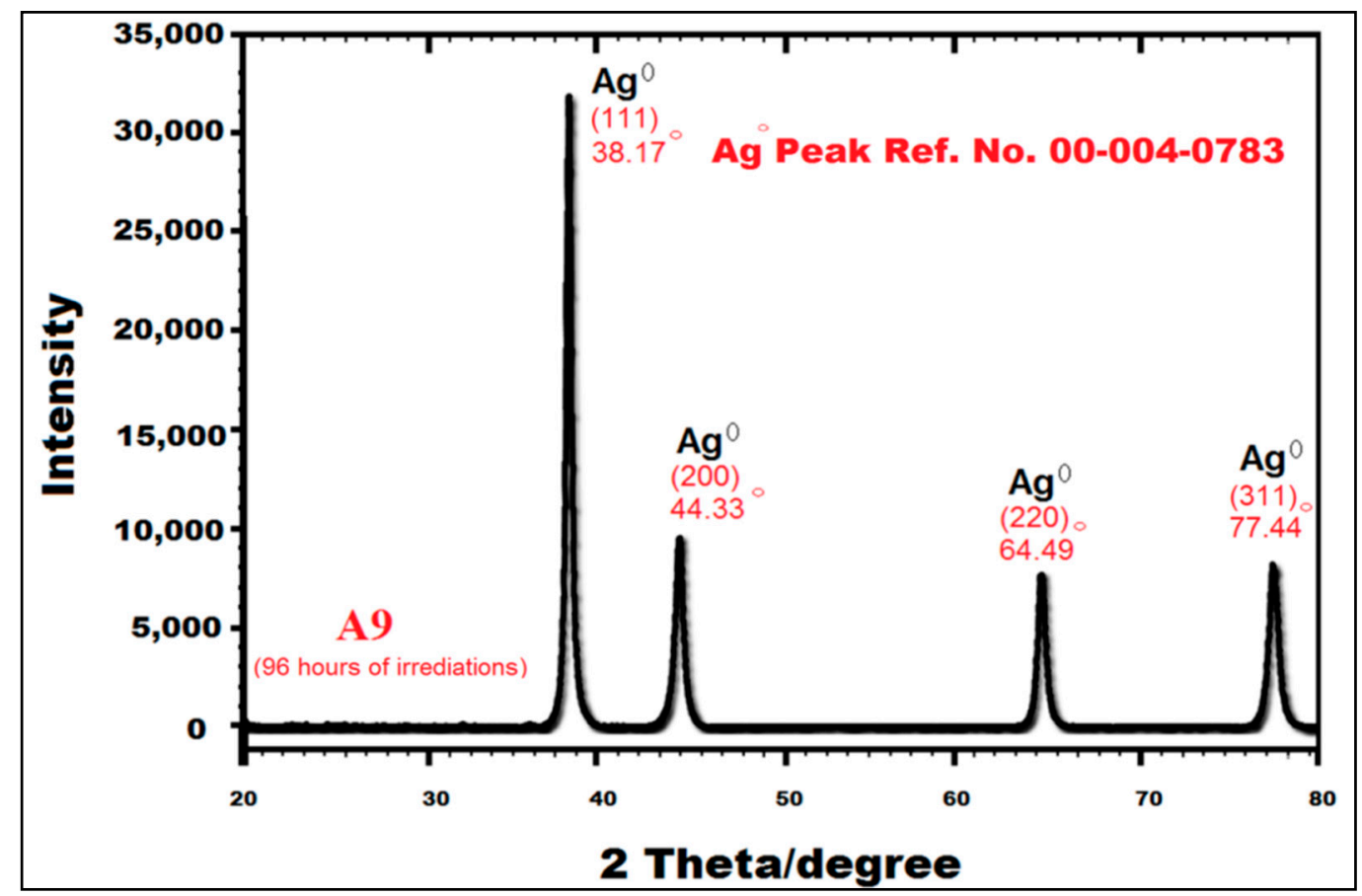

Figure 3. Powder X-ray diffraction (PXRD) spectra for P-AgNPs obtained after $96 \mathrm{~h}$ of UV irradiation.

Similar findings have been reported for the typical PXRD spectra of AgNPs with four diffraction peaks $(111,200,220,311)$ by Coseri et al. [30]. A four diffraction peak pattern of AgNPs confirms the "fcc" topographic nature of NPs [17,30,32]. Bankura et al. [17] and Roopan [20] had previously reported that the four peak pattern at 2-theta/degree could be due to the crystallization of reducing and capping agent used for the synthesis of Ag NPs.

The topographic structure and shape of P-AgNPs was confirmed as "spherical" by field emission scanning electron microscopy (FESEM) (Figure 4A,B). The FESEM micrographs of P-AgNPs revealed the presence of spherical shaped P-AgNPs at 10,000×. Our study was in agreement with the findings of Saravanan et al. [24], for the distribution of spherical shaped "bacterial exo-polysaccharide AgNPs. The mean crystalline size of NPs was observed as $42.27 \pm 12.2 \mathrm{~nm}$ after $48 \mathrm{~h}$ of UV irradiation (Figure 4C) and $6.02 \pm 2.37 \mathrm{~nm}$ after $96 \mathrm{~h}$ of UV irradiation (Figure 4D), as confirmed by high resolution transmission electron microscopy (HRTEM). The decrease in crystalline size of P-AgNPs from $48 \mathrm{~h}$ to $96 \mathrm{~h}$ of UV irradiation, was proven by HRTEM analysis, along with "quasi-spherical" characteristics, as per reports by Quester et al. [39]. The typical "quasi-spherical" nature is one of the prominent shape characteristics of AgNPs for their application in various fields [40]. By HRTEM observation at $5 \mathrm{~nm}$, it was found that P-AgNPs were delimited by a thin layer of an organic material (Figure 4E) which is supposed to be the reducing and the capping agent pullulan [40]. The top to top distance, between the surface lattice of AgNPs, was $0.235 \mathrm{~nm}$ (Figure 4E) in selected area electron diffraction (SAED) analysis (Figure 4F) [41]. 

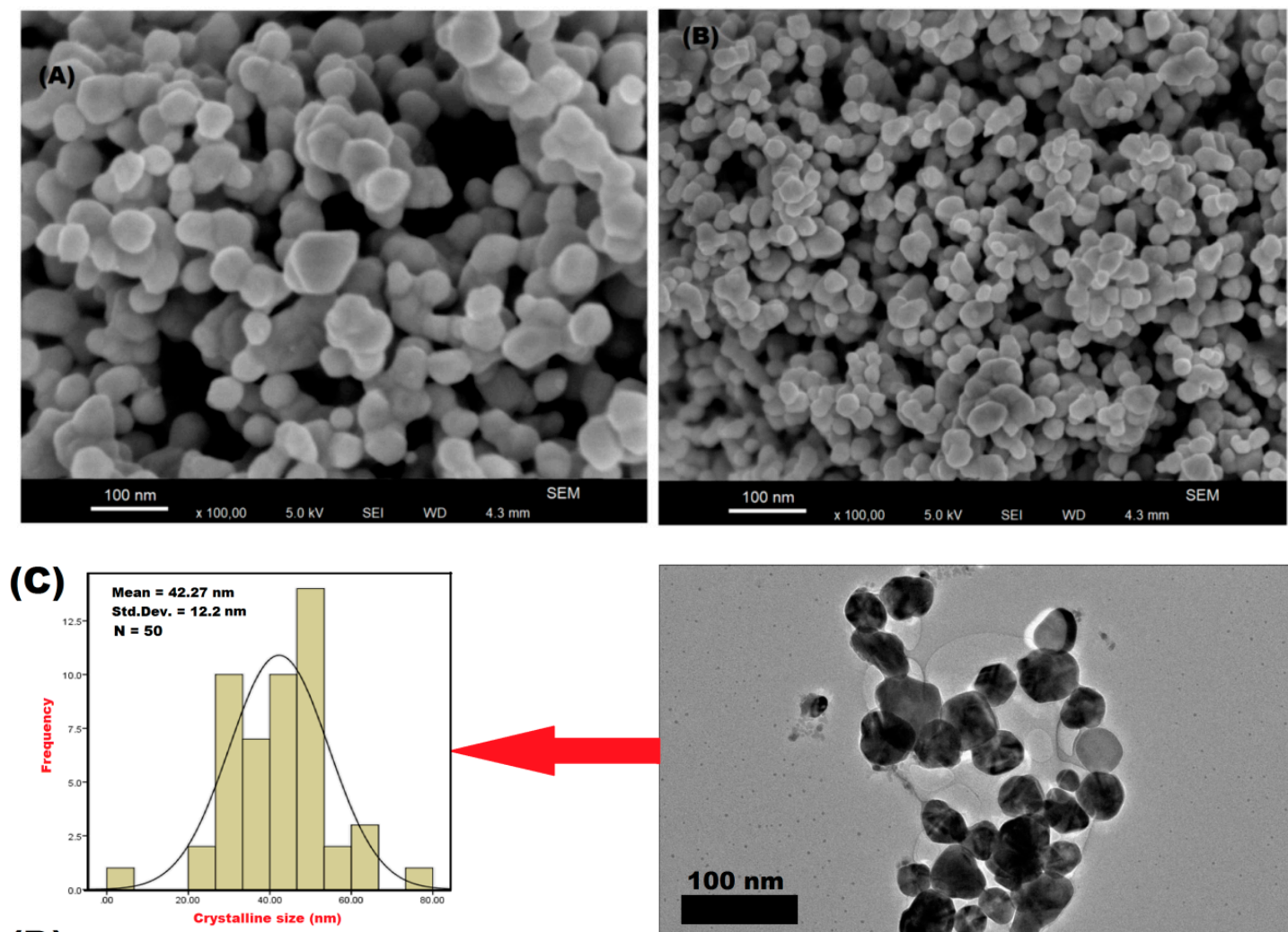

(D)
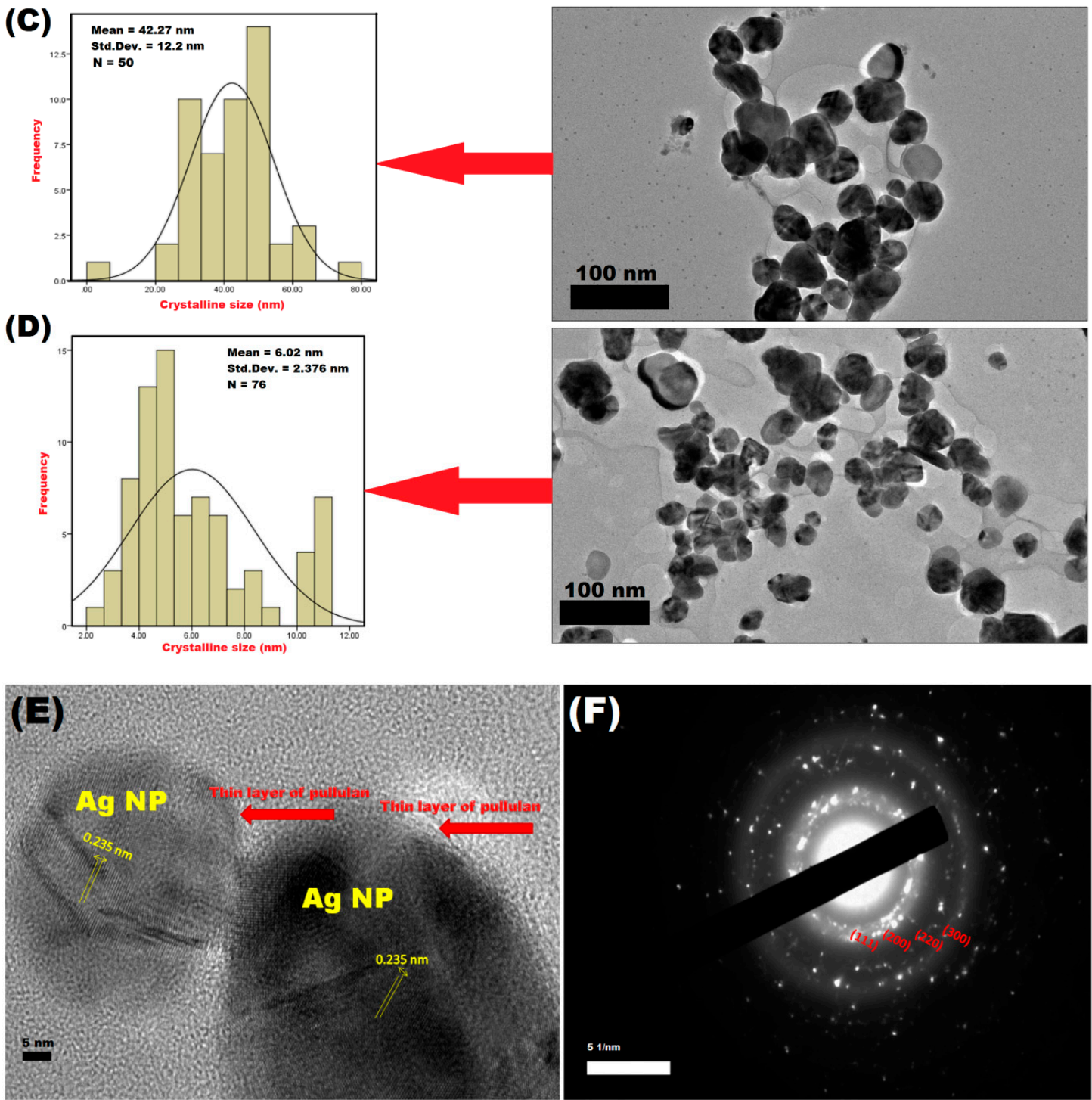

Figure 4. (A) FESEM micrograph of P-AgNPs after $48 \mathrm{~h}$ of UV irradiation. (B) FESEM micrograph of P-AgNPs after $96 \mathrm{~h}$ of UV irradiation. (C) HRTEM image showing the topography and mean crystalline size of P-AgNPs after $48 \mathrm{~h}$ of UV irradiation. (D) HRTEM image of P-AgNPs after $96 \mathrm{~h}$ of UV irradiation, showing the topography and mean crystalline size. (E) Lattice surface analysis of P-AgNPs after $96 \mathrm{~h}$ of UV irradiation. (F) Selected area electron diffraction (SAED) of P-AgNPs after $96 \mathrm{~h}$ of UV irradiation. 
The possible involvement of the functional groups of pullulan for the synthesis of P-AgNPs was studied by FT-IR spectra. Pullulan aqueous solution $(10 \% \mathrm{w} / \mathrm{v}$, without UV irradiation) was compared with pullulan $+\mathrm{AgNO}_{3}$ colloidal solution (with $96 \mathrm{~h}$ of UV irradiation, A9). It can be observed that P-AgNPs expressed their characteristic peaks from wave numbers $3925 \mathrm{~cm}^{-1}$ to $1325 \mathrm{~cm}^{-1}$ (Figure 5a). The first strong and broader peak was at $3359 \mathrm{~cm}^{-1}$ (Figure 5a) indicating the stretching and involvement of hydroxyl $(\mathrm{O}-\mathrm{H})$ group of pullulan [31].
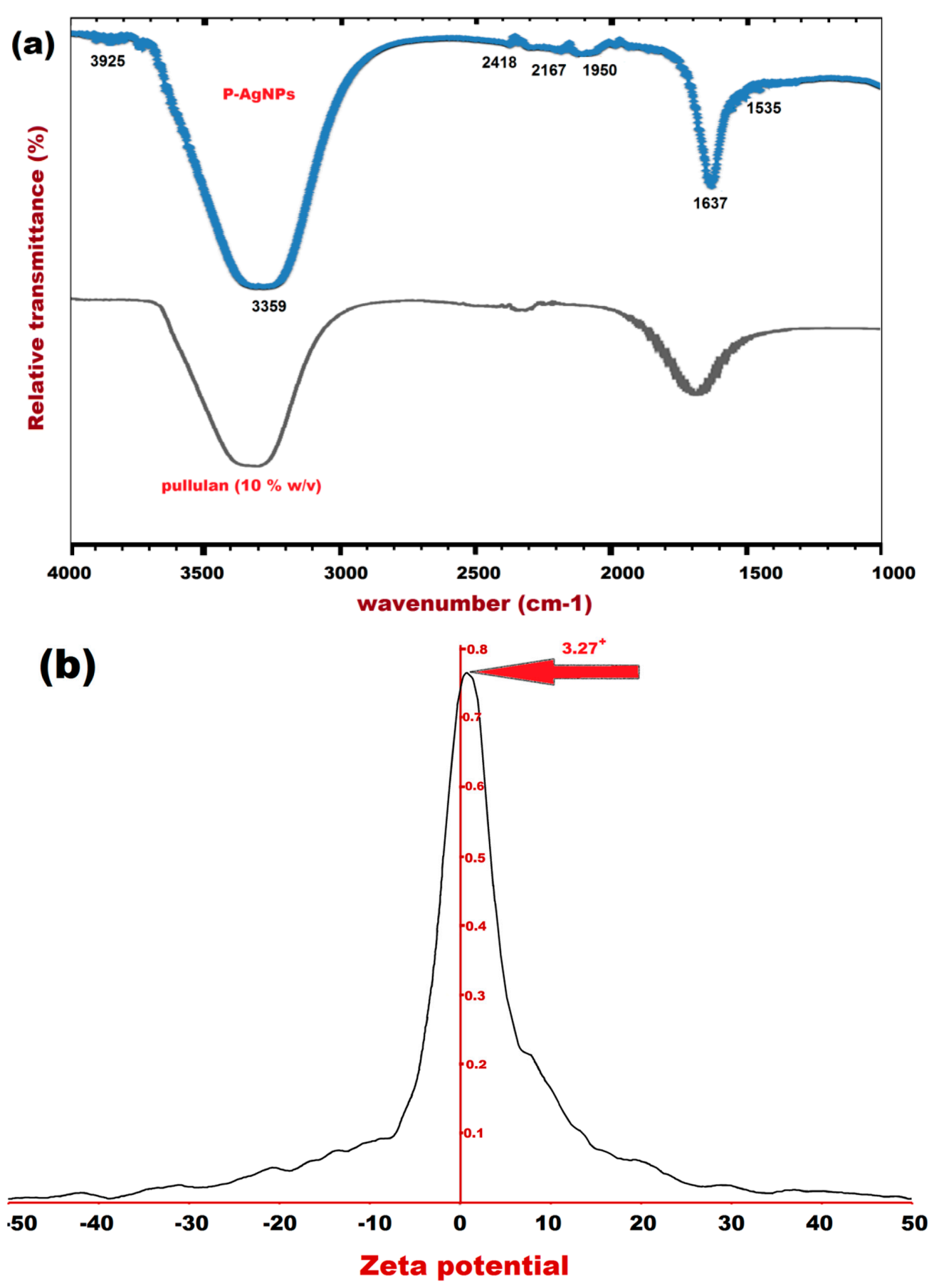

Figure 5. (a) FT-IR spectra of pullulan (10\%) and P-AgNPs (b) Zeta potential of P-AgNPs.

The O-H group of pullulan is considered as an efficient coordinator with silver ions of P-AgNPs during the reduction process [34]. The prominent peaks were at wave numbers $2418,2167,1950,1637$, and $1535 \mathrm{~cm}^{-1}$ (Figure $5 \mathrm{a}$ ), proving the stretching frequencies of carbonyl $(\mathrm{C}=\mathrm{O})$ and $\mathrm{C}=\mathrm{C}$ groups of 
pullulan $[31,32,42]$. For the involvement and the stretching frequencies of $\mathrm{C}=\mathrm{O}$ and $\mathrm{C}=\mathrm{C}$ functional groups, the standard wave numbers range from $1000 \mathrm{~cm}^{-1}$ to $1900 \mathrm{~cm}^{-1}$ [31]. The FT-IR spectral results were in agreement with the reports of Ganduri et al. [31], Kanmani and Lim [32] and Kumar et al. [41] for the involvement of $\mathrm{O}-\mathrm{H}, \mathrm{C}=\mathrm{O}$ and $\mathrm{C}=\mathrm{C}$ groups of pullulan during the synthesis of $\mathrm{P}$-AgNPs.

The zeta potential of P-AgNPs was confirmed as $3.27^{+}$(Figure $5 \mathrm{~b}$ ), proving "stability" of the NPs in the colloidal solution at $25^{\circ} \mathrm{C}$ and pH 6.34 [34]. Pullulan has an "uncharged nature" in the colloidal solution when used as the reducing and capping agent [30]. Due to the positive charge at the core, P-AgNPs exhibited positive zeta potential in the solution, with better stability $[30,34]$. Pullulan concentration, in the formation of P-AgNPs, can also govern zeta potential (ZP) with positive or negative charges at room temperature [30].

\section{Conclusions}

An environment friendly, economical, safer and green physical technique has been introduced for the synthesis of P-AgNPs. Pullulan was used as a "green" capping, stabilizing and reducing agent without any addition of toxic or harmful chemicals. The effect of UV irradiation time was also recorded as the main factor for controlling the synthesis, size, shape and distribution of the nanoparticles. Green synthesized P-AgNPs contained "quasi-spherical characteristics" showing $415 \mathrm{~nm}$ as spectra maxima with mean crystalline size of $6.02 \pm 2.37 \mathrm{~nm}$ after $96 \mathrm{~h}$ of UV irradiation. The crystallographic nature of P-AgNPs was recorded as "face centered cubic" surrounded by a thin layer of pullulan. The involvement of $\mathrm{O}-\mathrm{H}, \mathrm{C}=\mathrm{O}$, and $\mathrm{C}=\mathrm{C}$ functional groups of pullulan, during the green synthesis, was confirmed by FT-IR spectra. Zeta potential of $3.27^{+}$confirmed the stability of P-AgNPs in the colloidal solution after $96 \mathrm{~h}$ of UV-irradiations. It is hypothesized that the green synthesized P-AgNPs can be utilized individually or incorporated in the active packaging with an antimicrobial potential due to their purity, smaller size and spherical shape.

\section{Abbreviations List}

$\begin{array}{ll}\text { NPs } & \text { Nanoparticles } \\ \text { UV } & \text { Ultraviolet } \\ \text { P-AgNPs } & \text { Pullulan mediated silver nanoparticles } \\ \text { FESEM } & \text { Field emission scanning electron microscopy } \\ \text { HRTEM } & \text { High resolution transmission electron microscopy } \\ \text { SAED } & \text { Selected area electron diffraction } \\ \text { PXRD } & \text { Powder X-ray diffraction } \\ \text { FT-IR } & \text { Fourier transform infrared spectroscopy } \\ \text { fcc } & \text { Face centered cubic } \\ \text { Rpm } & \text { Revolution per minute } \\ \text { w/v } & \text { Weight/volume } \\ \text { M solution } & \text { Molar solution }\end{array}$

Author Contributions: Conceptualization: M.J.K., S.K., K.S. and A.Q.S.; methodology and software: M.J.K.; validation and data curation: M.J.K. and K.S.; formal analysis and investigation: M.J.K. and S.K.; writing, reviewing and editing: M.J.K., S.K., K.S., J.S. and A.Q.S.

Funding: Research Management Centre, UPM-MTDC Technology Centre, University of Putra Malaysia, 43400 UPM Serdang, Selangor, Malaysia, with research grant (VOT) No. GP-IMP/2017/9555400.

Acknowledgments: All the authors are grateful to the Research Management Centre; UPM-MTDC Technology Centre; and University of Putra Malaysia, 43400 UPM Serdang, Selangor, Malaysia; for providing the Putra grant and those who supported for this project.

Conflicts of Interest: All the authors state no conflict of interest. 


\section{References}

1. Alexis, F.; Pridgen, E.; Molnar, L.K.; Farokhzad, O.C. Factors Affecting the Clearance and Biodistribution of Polymeric Nanoparticles. Mol. Pharm. 2008, 5, 505-515. [CrossRef] [PubMed]

2. Wyser, Y.; Adams, M.; Avella, M.; Carlander, D.; Garcia, L.; Pieper, G.; Weiss, J. Outlook and challenges of nanotechnologies for food packaging. Packag. Technol. Sci. 2016, 29, 615-648. [CrossRef]

3. Huang, Y.; Mei, L.; Chen, X.; Wang, Q. Recent Developments in Food Packaging Based on Nanomaterials. Nanomaterials 2018, 8, 830. [CrossRef]

4. Mittal, V. Polymer Layered Silicate Nanocomposites: A Review. Materials 2009, 2, 992-1057. [CrossRef]

5. Salarbashi, D.; Mortazavi, S.A.; Noghabi, M.S.; Fazly-Bazzaz, B.S.; Sedaghat, N.; Ramezani, M.; Shahabi-Ghahfarrokhi, I. Development of new active packaging film made from a soluble soybean polysaccharide incorporating ZnO nanoparticles. Carbohydr. Polym. 2016, 140, 220-227. [CrossRef] [PubMed]

6. Cushen, M.; Kerry, J.; Morris, M.; Cruz-Romero, M.; Cummins, E. Migration and exposure assessment of silver from a PVC nanocomposite. Food Chem. 2013, 139, 389-397. [CrossRef]

7. Lara, H.H.; Ayala-Núñez, N.V.; Ixtepan-Turrent, L.; RodríguezPadilla, C. Bactericidal effect of silver nanoparticles against multidrug-resistant bacteria. World J. Microbiol. Biotechnol. 2010, 26, 615-621. [CrossRef]

8. Lara, H.H.; Garza-Treviño, E.N.; Ixtepan-Turrent, L.; Singh, D.K. Silver nanoparticles are broad-spectrum bactericidal and virucidal compounds. J. Nanobiotechnol. 2011, 9, 30. [CrossRef]

9. Zhang, K.; Ai, S.; Xie, J.; Xu, J. Comparison of direct synthesis of silver nanoparticles colloid using pullulan under conventional heating and microwave irradiation. Inorg. Nano-Met. Chem. 2017, 47, 938-945. [CrossRef]

10. Raveendran, P.; Fu, J.; Wallen, S.L. Completely "green" synthesis and stabilization of metal nanoparticles. J. Am. Chem. Soc. 2003, 125, 13940-13941. [CrossRef]

11. Dubiel, M.; Heinz, M.; Srabionyan, V.V.; Pryadchenko, V.V.; Avakyan, L.A.; Zubavichus, Y.V.; Bugaev, L.A. Silver nanoparticles in silicate glass prepared by UV laser irradiation: Dependences of size and atomic structure of particles upon irradiation parameters. J. Phys. Conf. Ser. 2016, 712, 8-12. [CrossRef]

12. Darroudi, M.; Ahmad, M.B.; Zak, A.K.; Zamiri, R.; Hakimi, M. Fabrication and characterization of gelatin stabilized silver nanoparticles under UV-Light. Int. J. Mol. Sci. 2011, 12, 6346-6356. [CrossRef] [PubMed]

13. Shameli, K.; Ahmad, M.B.; Yunus, W.M.Z.W.; Rustaiyan, A.; Ibrahim, N.A.; Zargar, M.; Abdollahi, Y. Green synthesis of silver/montmorillonite/chitosan bionanocomposites using the UV irradiation method and evaluation of antibacterial activity. Int. J. Nanomed. 2010, 5, 875-887. [CrossRef] [PubMed]

14. Aceh, B.; Saleha, S. Preparation and characterization edible film packaging from carrageenan. Proc. Ann. Int. Conf. Syiah Kuala Univ. 2013, 3, 44-50.

15. Varaprasad, K.; Vimala, K.; Ravindra, S.; Narayana-Reddy, N.; VenkataSubbaReddy, G.; MohanaRaju, K. Fabrication of silver nanocomposite films impregnated with curcumin for superior antibacterial applications. J. Mater. Sci. Mater. Med. 2011, 22, 1863-1872. [CrossRef] [PubMed]

16. Chen, X.; Zou, L.Q.; Niu, J.; Liu, W.; Peng, S.F.; Liu, C.M. The stability, sustained release and cellular antioxidant activity of curcumin nanoliposomes. Molecules 2015, 20, 14293-14311. [CrossRef] [PubMed]

17. Bankura, K.P.; Maity, D.; Mollick, M.M.R.; Mondal, D.; Bhowmick, B.; Bain, M.K. Synthesis, characterization and antimicrobial activity of dextran stabilized silver nanoparticles in aqueous medium. Carbohydr. Polym. 2012, 89, 1159-1165. [CrossRef] [PubMed]

18. Bindhu, M.R.; Umadevi, M. Synthesis of monodispersed silver nanoparticles using Hibiscus cannabinusleaf extract and its antimicrobial activity. Spectrochim. Acta Part A Mol. Biomol. Spectrosc. 2013, 101, 184-190. [CrossRef] [PubMed]

19. Kalishwaralal, K.; BarathManiKanth, S.; RamKumarPandian, S.; Deepak, V.; Gurunathan, S. Silver nanoparticles impede the biofilm formation by Pseudomonas aeruginosa and Staphylococcus epidermidis. Colloids Surf. B Biointerface 2010, 79, 340-344. [CrossRef] 
20. Roopan, S.M.; RohitMadhumitha, G.; Abdul-Rahumanb, A.; Kamaraj, C.; Bharathi, A.; Surendra, T.V. Low-cost and eco-friendly phytosynthesis of silver nanoparticles using Cocos nuciferacoir extract and its larvicidal activity. Ind. Crops Prod. 2013, 43, 631-635. [CrossRef]

21. Wei, X.; Luo, M.; Li, W.; Yang, L.; Liang, X.; Xu, L. Synthesis of silver nanoparticles by solar irradiation of cell-free Bacillus amyloliquefaciens extracts and $\mathrm{AgNO}_{3}$. Bioresour. Technol. 2012, 103, 273-278. [CrossRef] [PubMed]

22. Chen, X.; Yan, J.K.; Wu, J.Y. Characterization and antibacterial activity of silver nanoparticles prepared with a fungal exopolysaccharide in water. Food Hydrocoll. 2016, 53, 69-74. [CrossRef]

23. Vasquez, R.D.; Apostol, J.G.; de-Leon, J.D.; Mariano, J.D.; Mirhan, C.M.C.; Pangan, S.; Zamora, E.T. Polysaccharide-mediated green synthesis of silver nanoparticles from Sargassumsiliquosum J.G. Agardh: Assessment of toxicity and hepatoprotective activity. OpenNano 2016, 1, 16-24. [CrossRef]

24. Saravanan, C.; Rajesh, R.; Kaviarasan, T. Synthesis of silver nanoparticles using bacterial exopolysaccharide and its application for degradation of azo-dyes. Biotechnol. Rep. 2017, 15, 33-40. [CrossRef] [PubMed]

25. Cheng, K.C.; Demirci, A.; Catchmark, J.M. Pullulan: Biosynthesis, production, and applications. Appl. Microbiol. Biotechnol. 2011, 92, 29. [CrossRef] [PubMed]

26. Duncan, T.V. Applications of nanotechnology in food packaging and food safety: Barrier materials, antimicrobials and sensors. J. Colloid Interface Sci. 2011, 363, 1-24. [CrossRef] [PubMed]

27. Kavya, A.; Du, X.; Liu, Z.; Lu, J.W.; Morris, J.R.; Glasser, W.G. Surfaceplasmon resonance studies of pullulan and pullulan cinnamate adsorption ontocellulose. Biomacromolecules 2008, 10, 2451-2459.

28. Wu, J.; Zhong, F.; Li, Y.; Shoemaker, C.F.; Xia, W. Preparation and characterization of pullulan-chitosan and pullulan-carboxymethyl chitosan blended films. Food Hydrocoll. 2013, 30, 82-91. [CrossRef]

29. Spatareanu, A.; Bercea, M.; Budtova, T.; Harabagiu, V.; Sacarescu, L.; Coseri, S. Synthesis, characterization and solution behaviour of oxidized Pullulan. Carbohydr. Polym. 2014, 111, 63-71. [CrossRef]

30. Coseri, S.; Spatareanu, A.; Sacarescu, L.; Rimbu, C.; Suteu, D.; Spirk, S.; Harabagiu, V. Green synthesis of the silver nanoparticles mediated by pullulan and 6-carboxypullulan. Carbohydr. Polym. 2015, 116, 9-17. [CrossRef]

31. Ganduri, V.S.R.K.; Mangamuri, U.; Muvva, V.; Poda, S. Pullulan-Stabilized Silver Nanoparticles-Their Synthesis, Characterization and Application as Bactericidal Agents. J. Appl. Pharm. Sci. 2016, 6, 027-037. [CrossRef]

32. Kanmani, P.; Lim, S.T. Synthesis and characterization of pullulan-mediated silver nanoparticles and its antimicrobial activities. Carbohydr. Polym. 2013, 97, 421-428. [CrossRef] [PubMed]

33. Trinetta, V.; Cutter, C.N. Pullulan: A Suitable Biopolymer for Antimicrobial Food Packaging Applications. Antimicrob. Food Packag. 2016, 385-397. [CrossRef]

34. Pandey, S.; Goswami, G.K.; Nanda, K.K. Green synthesis of biopolymer-silver nanoparticle nanocomposite: An optical sensor for ammonia detection. Int. J. Biol. Macromol. 2012, 51, 583-589. [CrossRef] [PubMed]

35. Esumi, K.; Hosoya, T.; Suzuki, A.; Torigoe, K. Formation of gold and silver nanoparticles in aqueous solution of sugar-persubstitutedpoly (amidoamine) dendrimers. J. Colloid Interface Sci. 2000, 226, 346-352. [CrossRef]

36. Kuthirummal, N.; Deana, A.; Yao, C.; Risen, J.W. Photo-formation of gold nanoparticles: Photoacoustic studies on solid monoliths of $\mathrm{Au}(\mathrm{III})$-chitosan-silica aerogels. Spectrochim. Acta Part A Mol. Biomol. Spectrosc. 2008, 70, 700-703. [CrossRef] [PubMed]

37. Huang, L.; Zhai, M.; Peng, J.; Xu, L.; Li, J.; Wei, G. Synthesis, size control and fluorescence studies of gold nanoparticles in carboxymethylated chitosan aqueous solutions. Colloid Interface Sci. 2007, 316, 398-404. [CrossRef]

38. Dubey, M.; Bhadauria, S.; Kushwah, B.S. Green synthesis of nano silver particles from extract of Eucalyptus hybrida (Safeda) leaf. Dig. J. Nanomater. Biostruct. 2009, 4, 537-543.

39. Quester, K.; Avalos-borja, M.; Castro-longoria, E. Controllable Biosynthesis of Small Silver Nanoparticles Using Fungal Extract. J. Biomater. Nanobiotechnol. 2016, 7, 118-125. [CrossRef]

40. Wang, C.; Gao, X.; Chen, Z.; Chen, Y.; Chen, H. Preparation, characterization and application of polysaccharide-based metallic nanoparticles: A review. Polymers 2017, 9, 689. [CrossRef] 
41. Kurian, M.; Varghese, B.; Athira, T.S.; Krishna, S. Novel and Efficient Synthesis of Silver Nanoparticles Using Curcuma Longa and Zingiber Officinale Rhizome Extracts. Int. J. Nanosci. Nanotechnol. 2016, 12, 175-181.

42. Kumar, B.; Smita, K.; Cumbal, L.; Debut, A.; Pathak, R.N. Sonochemical Synthesis of Silver Nanoparticles Using Starch: A comparison. Bioinorg. Chem. Appl. 2014, 2014, 784268. [CrossRef] [PubMed]

(C) 2019 by the authors. Licensee MDPI, Basel, Switzerland. This article is an open access article distributed under the terms and conditions of the Creative Commons Attribution (CC BY) license (http://creativecommons.org/licenses/by/4.0/). 